\title{
Richard G. Wick Alexander
}

- Mestre pela University of Texas.

- Professor Clínico da Baylor College of Dentistry desde 1965 e também na University of Texas e New York University.

- Criador da Disciplina de Alexander e dos braquetes Mini-Wick e Alexander Signature Line.

- Fundador da Alexander Foundation for Orthodontic Research and Education.

- Revisor de várias revistas internacionais.

- Escreveu dois livros e publicou, até esta data, 45 artigos científicos em revistas indexadas.

- Membro da "Task force" original da Ormco, que iniciou os estudos na Ortodontia lingual.

- Palestrou extensivamente pelos EUA e por mais 62 países, incluindo o Brasil.

- Diretor-geral (eleito) da Angle Society.

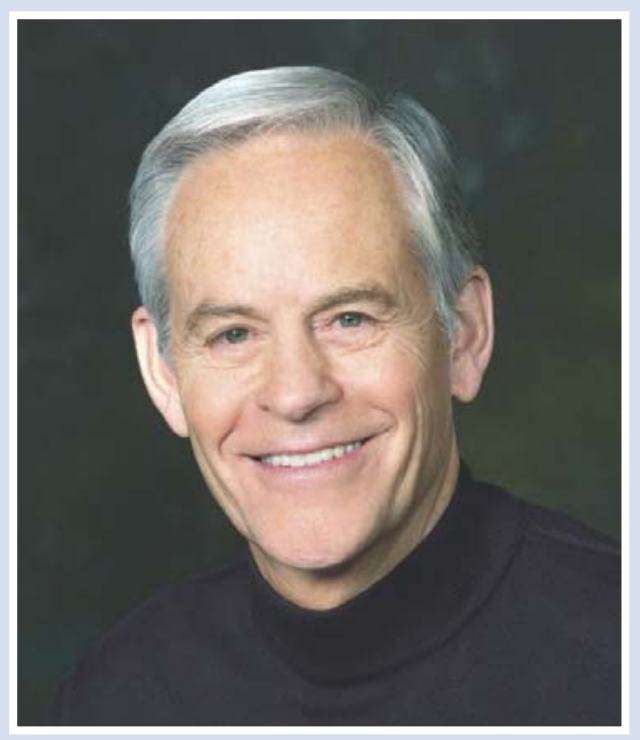

O Dr. Richard G. Wick Alexander iniciou uma vida de consagração como especialista em Ortodontia, formando-se Mestre pela Universidade do Texas em 1964 e iniciando sua carreira acadêmica como professor no Baylor College of Dentistry em 1965, cargo que ocupa até hoje. Paralelamente, ele ainda é professor adjunto das Universidades do Texas e de Nova York. Em 1978, a partir de seus achados clínicos (embasados inicialmente na técnica de Tweed) e científicos, o Dr. Wick idealizou a Disciplina de Alexander, tendo tratado em seu consultório mais de 14.000 pacientes, permitindo-lhe uma inigualável biblioteca de documentações ortodônticas. Este acervo tem sido utilizado como fonte de pesquisa por alunos de pós-graduação de diversos países. A sua visão arrojada de administração de consultórios, advinda do trabalho com seus filhos em uma movimentada clínica de Ortodontia em Arlington, no Texas, oferece a possibilidade de tratamentos de alta qualidade para uma terceira geração de pacientes. Isto faz do Dr. Wick Alexander um ícone da Ortodontia internacional, palestrando em diversos congressos de renome, inclusive, anualmente, no congresso americano de Ortodontia. 
1) Durante o processo de diagnóstico, a qual exame o Sr. dá mais crédito: análise facial ou cefalométrica? Cássio Selaimen

$\mathrm{O}$ que você faria se estivesse avaliando o seu filho? A face é sempre prioritária! Entretanto, nós devemos nos preocupar com a estabilidade em longo prazo.

Equilibrar estes dois fatores é um desafio que encontramos no diagnóstico e plano de tratamento. Na maioria das vezes, entretanto, o posicionamento correto dos dentes produzirá um perfil equilibrado.

\section{2) Quais os fundamentos básicos que - aluno de especialização em Ortodon- tia necessita, para obter melhor apro- veitamento da Disciplina de Alexander? Ricardo Lombardi de Farias \\ Os estudantes em Ortodontia devem, antes} de aprender a Disciplina, ter um entendimento dos fundamentos básicos da biomecânica de ancoragem, de torque, off-sets e dobras em geral, da oclusão funcional, necessária à estabilidade dos casos e entendimento sobre a influência do perfil mole. Também devem ter noção sobre quando extrair ou não extrair. Nossa técnica foi construída sobre os conceitos que aprendi devido ao meu treinamento na técnica de Tweed. Se eu pudesse dar um conselho aos alunos de Ortodontia, eu recomendaria a todos que fizessem o curso da Tweed Foundation, se possível.

3) Gosto muito do seu livro ${ }^{1}$ e utilizei muito os capítulos iniciais durante a implantação da minha clínica. O Sr. acha vantajoso delegar funções clínicas aos auxiliares? Cássio Selaimen

Fico feliz em saber que meu livro teve algum valor quando você começou a sua clínica. Aprender a delegar funções propriamente é um dos fatores que têm uma profunda influência no tratamento ortodôntico contemporâneo. Eu delego os procedimentos que eu consigo ensinar a alguém, contanto que essa pessoa consiga fazer o procedimento tão bem quanto eu. Posicionamento de braquetes, escolha do formato dos arcos, escolha de onde usar os elásticos, arcos extrabucais, dentre outros procedimentos, são minha responsabilidade.

4) O Sr. realiza o tratamento em duas fases em sua clínica? Se afirmativo, em quais situações você indica o tratamento interceptador e quando você inicia o tratamento destes pacientes? Renato Parsekian Martins

Em termos gerais, trate as pacientes do gênero feminino... deixe que os homens cresçam e trateos mais tarde.

O tratamento precoce deve ser iniciado quando os problemas que os pacientes possuem irão deteriorar, ou melhor, piorar se não forem tratados. Geralmente, eu começo após os incisivos laterais terem irrompido. Outro aspecto que vale a pena ser mencionado é que hoje eu acredito ser imprudente extrair os caninos decíduos, na maioria dos casos.

5) Qual a seqüência de fios que o Sr. acha mais interessante para casos simples de alinhamento e nivelamento? Cássio Selaimen

Dependendo da necessidade de controle de torque, eu utilizo um fio flexível 0,016" de NiTi ou um 0,017 " x 0,025 " de NiTi. Daí, eu procedo para um arco intermediário de aço inoxidável 0,016 " ou 0,016 " x 0,022 " e, finalmente, finalizo com um arco 0,017 " x 0,025" de aço inoxidável com ômegas amarrados.

6) O Sr. tem demonstrado, ao longo dos anos, uma atitude menos extracionista. Em quais casos acha que extrações dentárias são realmente necessárias? Luiz Gonzaga Gandini Jr.

A extração de dentes é um procedimento irreversível! Indique com cautela! No início do meu treinamento em Ortodontia, nós não tínhamos conhecimento da "expansão". Hoje nós sabemos que a expansão posterior pode ser estável em alguns tipos de pacientes em crescimento. Ao ganhar espaço com expansões, nesses casos em particular, nós podemos transformar um diagnóstico de extração em um de não-extração.

Extrações ainda são necessárias em casos de 
discrepâncias severas de comprimento de arco $(\geq 7 \mathrm{~mm})$ e em casos de perfil excessivamente convexo. É claro que para toda regra há uma exceção, por isso nós precisamos estudar cuidadosamente o caso e toda a documentação antes de tomar uma decisão final.

7) Como o Sr. compara o sistema Wick Alexander ao sistema de autoligáveis, considerando menos extrações, menor friç̧ão, maior intervalo entre as consultas e rapidez na finalização? Luiz Garcia

Lembre-se, braquetes não mudam a biologia! Há uma vantagem nos braquetes autoligáveis... a de amarrar os arcos mais rapidamente (podese levar uma quantidade razoável de tempo para amarrar o arco inicial que apresente um alto grau de apinhamento). Sistemas autoligáveis apresentam um problema sério em termos de finalização. Com a minha técnica pode-se alcançar excelentes finalizações.

Eu acredito que o tempo vai expor a verdade sobre atrito e tratamentos "rápidos". Há tantos outros fatores que somam-se para determinar o tempo de tratamento - diagnóstico, crescimento, cooperação. E, realmente, me responda: "O que você prefere? Um tratamento rápido ou um tratamento de maior qualidade?"

Qualquer técnica pode ser menos extracionista. O desafio é colocar os dentes em suas posições adequadas para que se possa dar ao paciente o melhor sorriso e estabilidade em longo prazo. Dentro deste enfoque, alguns pacientes precisam ser tratados com extrações.

8) Para a finalização de alguns casos temos observado a necessidade de acrescentar offset ou diminuir o torque dos caninos superiores, pois os mesmos se apresentam com as suas coroas muito inclinadas para lingual. Em sua casuística, este procedimento tem sido comumente executado? Irene Ueti Lombardi de Farias

Eu não tenho vivenciado a necessidade de utilizar off-sets de caninos. Este pode ser um proble- ma de posicionamento dos braquetes. A altura dos braquetes deve ser de $4 \mathrm{~mm}$ nos laterais superiores, $5 \mathrm{~mm}$ nos caninos superiores e $4,5 \mathrm{~mm}$ no primeiro pré-molar. $\mathrm{O}$ posicionamento correto destes braquetes fará com que a "expressão" do aparelho chegue à perfeição.

9) O Sr. fez parte da equipe original da Ormco que desenvolveu um dos primeiros braquetes linguais. Ainda trata pacientes com este sistema? Em quais casos? Lídia Parsekian Martins

Devido à popularidade do Invisalign, muitos pacientes adultos têm nos consultado procurando este tipo de tratamento. Quando não é indicado para o caso, sugerimos o aparelho lingual. A terceira escolha seriam os braquetes cerâmicos.

Via de regra, eu uso os braquetes linguais em pacientes adultos ou em adolescentes mais velhos que solicitam aparelhos invisiveis.

Os aparelhos linguais funcionam. A tecnologia usada hoje pelo iBraces torna o tratamento por lingual muito mais simples do que com os braquetes linguais convencionais. A melhor característica deste aparelho lingual é que os fios são produzidos junto e especificamente para um conjunto de braquetes.

10) Qual a sua justificativa para tratar a grande maioria das más oclusões de Classe II com aparelho extrabucal, sendo que a literatura caminha cada vez mais para aparelhos que estimulam o crescimento mandibular? Luiz Gonzaga Gandini Jr.

Se você checar a literatura mais recente, descobrirá que nenhum aparelho ortopédico estimula o crescimento mandibular. $\mathrm{O}$ arco extrabucal e os aparelhos ortopédicos têm o mesmo efeito. Eles "seguram" a maxila, permitindo que, enquanto isso, a mandíbula cresça.

A razão pela qual prefiro o aparelho extrabucal é que este não promove vestibularização dos incisivos inferiores e nem gera mordida dupla, como acontece com os aparelhos ortopédicos funcionais. 
11) Existe alguma evidência de sobrecarga radicular durante a mecânica de Classe II e de Classe III através da utilização dos elásticos intermaxilares apoiados, respectivamente, nos incisivos laterais superiores e inferiores, uma vez que as raízes dos mesmos são menores que as dos caninos? Irene Ueti Lombardi de Farias

Não! Nós temos executado este tipo de mecânica por 40 anos e teríamos percebido reabsorções se isso fosse um problema. Você mesmo pode observar os nossos estudos em longo prazo e ver os resultados. Mas lembre-se, quando usar elásticos, ambos os arcos devem estar amarrados.

12) No que difere o tratamento da má oclusão de Classe II no que diz respeito ao padrão de crescimento dos pacientes? Renato Parsekian Martins

Pacientes portadores de má oclusão de Classe II braquicefálicos são tratados com aparelho extrabucal com tração cervical e elásticos de Classe II para corrigir os problemas esqueléticos. Pedimos para que os pacientes usem o aparelho extrabucal por 8 a 9 horas toda a noite. Esses pacientes normalmente respondem bem ao tratamento, devido ao seu excelente potencial de crescimento.

Os pacientes verticais devem usar o aparelho extrabucal com tração occipital. Exercícios de "apertamento", terapia miofuncional e elásticos verticais são utilizados como auxiliares ao tratamento. As más oclusões destes pacientes são mais difíceis de serem tratadas e não é sempre que esses pacientes respondem bem ao tratamento.

13) Quais foram as inovações mais interessantes introduzidas nos seus conceitos e técnica de tratamento ortodôntico nos últimos 10 anos? Luiz Garcia

As "verdades" fundamentais não mudaram nesses anos, com a exceção da expansão posterior.

Com a introdução dos fios da "era espacial", pode-se ver os pacientes menos vezes, em consultas mais espaçadas. Também tenho utilizado elásticos verticais mais cedo no tratamento de pacientes com mordidas abertas e mordidas profundas.

Os dispositivos de ancoragem temporária (ex.: mini-implantes) podem ter um efeito tremendo na nossa biomecânica básica. Eles se tornarão comuns em pacientes adultos mutilados e poderão também controlar ou melhorar a dimensão vertical em indivíduos dolicocefálicos.

Nós temos aprendido muito sobre estabilidade, sobre onde os dentes devem estar ao final do tratamento. Eu continuo tentando cada vez mais acertar minha "sintonia fina" para alcançar uma melhor finalização.

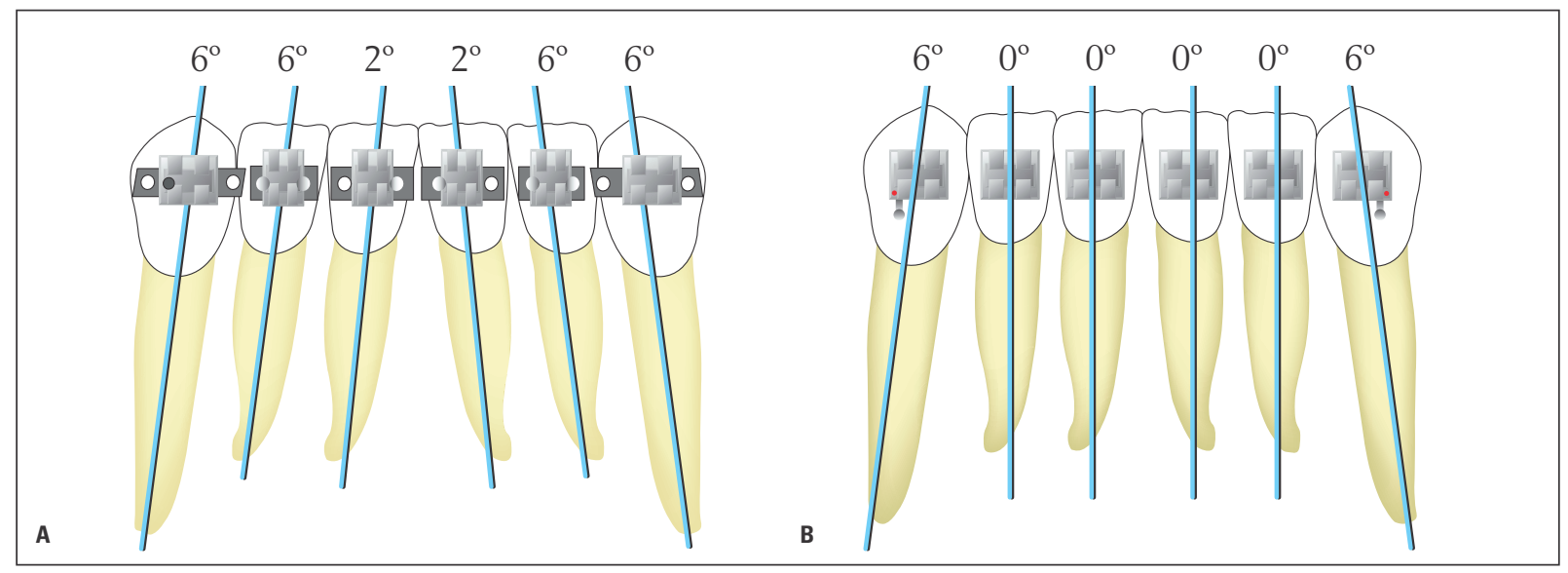

FIGURA1 - Na prescrição Alexander, as raízes dos incisivos centrais e laterais inferiores apresentam inclinações para distal (A), quando comparadas ao posicionamento radicular de outras prescrições $\mathbf{( B )}$. 


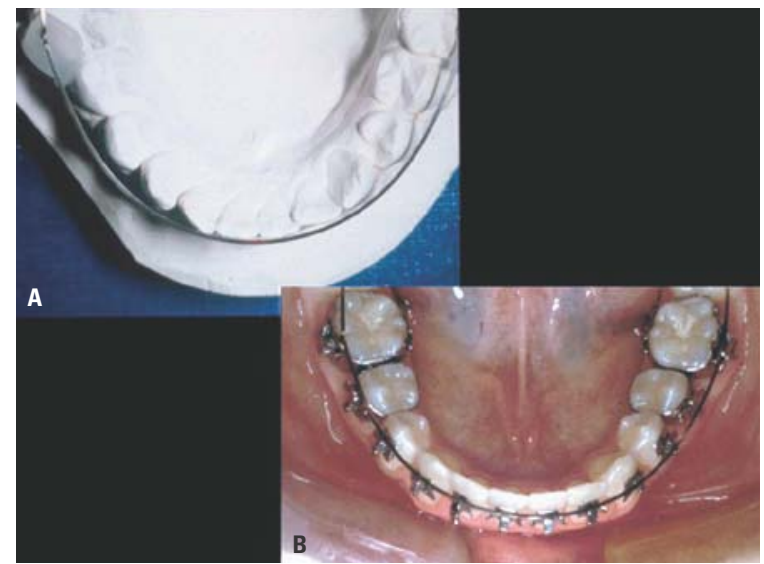

FIGURA 2 - Na Disciplina de Alexander a distância intercaninos original deve ser respeitada (A). Observar a forma do arco a ser instalado (B).

14) O Sr. tem utilizado mini-implantes e colagem indireta na sua clínica particular de maneira sistemática? Lídia Parsekian Martins

Dispositivos de ancoragem temporária estão se tornando cada vez mais comuns em casos específicos, como eu descrevi anteriormente. Com o passar do tempo, e com uma maior experiência, este recurso será um grande aliado do ortodontista.

A técnica de colagem indireta usada com o nosso sistema de braquetes foi criada pelo meu sobrinho, o Dr. Cliff Alexander. Nós hoje utilizamos essa abordagem indireta para a colagem de todos os braquetes. É altamente eficiente e eficaz.

15) Quais são as principais chaves para o sucesso em longo prazo, do ponto de vista da estabilidade? Luiz Gonzaga Gandini Jr.

A estabilidade ainda continua a ser debatida dentro da comunidade ortodôntica. Depois de anos de estudo e pesquisa eu cheguei a uma conclusão muito simples: KISS (N.T.: KISS ="Keep It Simple Sir" ou Mantenha Tudo Simples Senhor - é o lema adotado na Disciplina Alexander). Controle os dentes inferiores de canino a canino: o ângulo IMPA, a distância intercaninos e promova divergência radicular dos dentes anteriores (Fig. 1).

Ao manter a distância intercaninos original, mas expandindo a distância intermolares até 34-38mm, o formato de arco final é criado (Fig. 2). Este formato de arco será "ovóide". Quase todos os casos terminados têm um formato de arco similar.

16) Qual é a sua estratégia para motivar os pacientes a serem colaboradores? Renato Parsekian Martins

Ame seus pacientes! Se eles sentirem esse amor, eles vão querer agradá-lo.

Acredito que o ortodontista deve:

1) confiar em sua técnica;

2) orientar adequadamente todos os envolvidos em seu consultório;

3) motivar os seus pacientes.

\section{REFERÊNCIAS}

1. ALEXANDER, R. G. WICK. A Disciplina de Alexander: Filosofia e conceitos contemporâneos. 1. ed. São Paulo: Editora Santos, 1997. 


\section{Cássio Selaimen}

- Doutor em Ortodontia pela UNESP - Araraquara.

- Mestre em Ortodontia pela UNESP - Araraquara.

- Membro da Associação Americana de Ortodontia.

- Clínica Particular em Porto Alegre - RS.

\section{Irene Ueti Lombardi de Farias}

- Mestre em Ortodontia pela FOUSP- São Paulo.

- Coordenadora do Curso de Especialização em Ortodontia da EAP-ABO /PB (Escola de Aperfeiçoamento Profissional da Associação Brasileira de Odontologia - seção Paraíba).

- Presidente da Sociedade Paraibana de Ortodontia.

\section{Lídia Parsekian Martins}

- Doutora em Ortodontia pela UNESP - Araraquara.

- Mestre em Ortodontia pela UNESP - Araraquara.

- Especialista em Ortodontia pela UNESP - Araraquara.

- Especialista em Odontopediatria pela UNESP - Araraquara.

- Professora Assistente Doutora da Disciplina de Ortodontia da UNESP - Araraquara.

\section{Luiz Gonzaga Gandini Jr.}

- Doutor em Ortodontia pela UNESP - Araraquara.

- Mestre em Ortodontia pela UNESP - Araraquara.

- Chefe da Pós-Graduação em Ciências Odontológicas.

- Assistant Adjunct Clinical Professor - Department of Orthodontic at Baylor College of Dentistry and Saint Louis University.

- Professor Livre-docente/Adjunto da Disciplina de Ortodontia - UNESP - Araraquara.

- Membro da Associação Americana de Ortodontia

- Revisor do American Journal of Orthodontics and Dentofacial Orthopedics e da Revista Dental Press de Ortodontia e Ortopedia Facial.

\section{Luiz Garcia}

- Mestre em Ortodontia pela USP- Bauru.

- Coordenador do Curso de Especialização em Ortodontia da EAP-ABO /Pernambuco (Escola de Aperfeiçoamento Profissional da Associação Brasileira de Odontologia).

- Professor de Ortodontia na Faculdade de Odontologia de Caruaru.

\section{Ricardo Lombardi de Farias}

- Doutor em Ortodontia pela UNESP - Araraquara.

- Mestre em Ortodontia pela FOUSP- São Paulo.

- Professor de Ortodontia do Curso de Especialização em Ortodontia da EAP-ABO/PB.

- Professor de Ortodontia da UFPB.

\section{Renato Parsekian Martins}

- Mestre em Ortodontia pela Faculdade de Odontologia de Araraquara - UNESP.

- Doutor em Ortodontia pela Faculdade de Odontologia de Araraquara - UNESP com bolsa sanduíche na Baylor College of Dentistry - Dallas, TX.

- Fellow Researcher da Baylor College of Dentistry - Dallas, TX.

- Professor do Curso de Especialização em Ortodontia da Faculdade de Odontologia de Araraquara - UNESP.

- Instrutor da Alexander Discipline International.

- Membro da Associação Americana de Ortodontia.

- Membro Aspirante da Angle Society. 